\title{
Exogenous acetic acid pre-treatment increases drought tolerance of two Indonesian foxtail millet (Setaria italica) accessions
}

\author{
CHOIROTIN NISA, NURUL JADID \\ Department of Biology, Faculty of Sciences and Data Analytics, Institut Teknologi Sepuluh Nopember. Jl. Arief Rahman Hakim - Surabaya, East Java, \\ Indonesia. Tel./fax.: +62-31-5963857, •email: nuruljadid@bio.its.ac.id
}

Manuscript received: 21 February 2021. Revision accepted: 29 March 2021.

\begin{abstract}
Nisa C, Jadid N. 2021. Exogenous acetic acid pre-treatment increases drought tolerance of two Indonesian foxtail millet (Setaria italica) accessions. Biodiversitas 22: 2117-2124. Drought is one of the external factors that affect the productivity of food crops. Some biotechnological approaches had been developed to increase plant resistance to drought stress. Moreover, an adjustment in plant cultivation system is also reported as alternative way to enhance plant resistance to water deficit conditions, especially during their initial vegetative phase. This study aimed to determine the effect of exogenous acetic acid pre-treatment on some Indonesian foxtail millet (Setaria italica) accessions under drought stress conditions. Two different foxtail millet accessions were used in this study: Gambir Manis and Polman Kuning. Morphological and physiological parameters were observed during this study, including plant height, number of leaves, root length, relative water content, total chlorophyll and carotenoid content, and panicle weight. Our results showed that all foxtail millet accessions survived drought stress condition after being pre-treated with exogenous acetic acid. Yet, some morphological parameters were significantly affected. Meanwhile, physiological parameters were not significantly affected. Overall, our data suggest that exogenous acetic acid pre-treatment could enhance drought avoidance in $S$. italica accessions. This might be due to acetic acid-induced jasmonic acid modulation and secondary metabolites production in S. italica during water deficit exposure.
\end{abstract}

Keywords: Acetic acid, drought avoidance, jasmonic acid, jewawut, Setaria italica

\section{INTRODUCTION}

Setaria italica is a carbohydrate-producing plant that has the potential to be developed as a functional food, especially in areas prone to drought. This plant originates from China and has been a traditional cereal crop in China since ancient times (Liu et al. 2011). The main producing areas for millet are the semi-arid plains in South Asia (particularly in India) and the Sahel region (south of the Sahara) in Africa (Amadou and Moussa 2018). Today millet has been cultivated in Andhra Pradesh, Karnataka, Maharashtra, Tamil Nadu, Rajasthan, Madhya Pradesh, Uttar Pradesh and the northeast states of India (Kumari et al. 2011). In Indonesia, S. italica is known as Jewawut, which is usually used as bird feed. Their cultivation as a food crops is still limited in several areas such as Bengkulu, South Sumatra, West Java and Papua (Sulistiyowati 2015). Some valuable nutritional characteristics of this crop include low glycemic index value (Jali et al. 2012), high protein content, and rich in dietary fiber (Amadou et al. 2013). In addition, it contains antioxidants (Almaski et al. 2017). Therefore, foxtail millet is also potential to be developed as a functional food. Jewawut grains contain $12.3 \%$ protein, $4.7 \%$ fat, and $60.6 \%$ carbohydrates (Kumari et al. 2011).

Jewawut is reported to be relatively drought tolerant (Lata et al. 2010 ; Lapuimakuni et al. 2018). Drought is one of the most significant abiotic stresses impeding global crop production. Although relatively drought-tolerant, the tolerance level of Jewawut to drought varies between genotypes (Begum et al. 2013 ; Lapuimakuni et al. 2018). Therefore, the selection of millet genotypes that are resistant to drought is very important. Basically, plants that are resistant to drought stress respond in 3 ways, morphological, physiological and molecular responses. Long period of drought stress will affect all metabolic processes in cells and consequently decrease plant productivity (Zlatev and Yordanov 2005). It can also trigger the formation of reactive oxygen species (ROS) (Asada 2006) and can consequently damage plant tissue and cell ultrastructure (Wise \& Naylor 1987).

Another physiological response of plants to drought stress is the accumulation of proline compounds. These compounds function to regulate the osmotic degree of cells (osmotic adjustment). An increase of proline accumulation in S.italica cv Prasad and Lepakshi during drought stress has been reported (Veeranagamallaiah et al. 2007; Pan et al. 2018). Morphological and anatomical responses have also been observed when plants are in drought stress condition. In addition, Ahanger et al. (2017) showed that plant defense mechanisms against drought stress involve transcription reprogramming, cell metabolism shifting, hormone signaling, and chromatin remodeling. The mechanism of plant resistance can be controlled by many genes (Tang et al. 2017). However, the study concerning the Indonesian local foxtail millet responses to drought stress is very limited.

Several studies have reported the aldehyde dehydrogenase $(A L D H)$ gene regulation in response to various conditions of abiotic stress. Overexpression of 
different $A L D H$ gene families in Arabidopsis thaliana enhances plant tolerance to drought stress (Kotchoni et al. 2006). In the Foxtail millet genome, $20 A L D H$ genes have been identified using qRT-PCR, including SiALDH11A1, which has increased expression in drought conditions (Zhu et al. 2014). In addition, the expression of Allene Oxide Synthase $(A O S)$ has also been reported to be involved in drought tolerance mechanisms. It involved in the biosynthesis of jasmonic acid (Pan et al. 2018; Xu et al. 2019). Recent studies have shown that acetic acid has a role related to the adaptation of plants to drought stress through the synthesis of jasmonic acid. Giving the evidence that exogenous acetic acid has succeeded in increasing drought tolerance in Arabidopsis, maize, rice, and wheat crops (Kim et al. 2018), however, the study of gene expression dynamics after pre-treatment of acetic acid in drought stress conditions has not been widely studied. Utsumi et al. (2019) reported that acetic acid treatment played a role in delaying the reduction of RWC (Relative Water Content) in drought-stressed plants. It also has been observed that acetic acid regulates jasmonic acid signaling and abscisic acid (ABA) biosynthesis in response to drought stress.

In this recent study, the effect of exogenous acetic acid pre-treatment in the initial vegetative phase of two different local accessions of Indonesian foxtail millet was observed. Our results showed different responses between the two local accessions against drought stress conditions. We also demonstrated that exogenous acetic acid treatment potentially enhances foxtail millet resistance against drought stress.

\section{MATERIALS AND METHODS}

\section{Study area}

The in vivo study for acetic acid pre-treatment and drought stress was conducted at the greenhouse facility of the Urban Farming area of the Institut Teknologi Sepuluh Nopember, Surabaya, Indonesia. Meanwhile, the morphological and physiological responses of the foxtail millet against drought stress was evaluated at the Laboratory of Bioscience and Plant Technology, Department of Biology, Institut Teknologi Sepuluh Nopember, Surabaya-Indonesia.

\section{Procedures}

Preparation of plant materials and cultivation media

Setaria italica seeds used in this study consisted of two accessions Polman Kuning (PK) and Gambir Manis (GM) which were local accessions obtained from the Indonesian Institute of Science (LIPI) Cibinong-Indonesia. The cultivation media used were obtained from PT Trubus Mitra Swadaya. A total of $2 \mathrm{~kg}$ soil was used in each polybag. Seed of $S$. italica were germinated on soil media and organic compost $(1: 1 \mathrm{v} / \mathrm{v})$ until 2 weeks, the watering process was carried out regularly according to the field capacity of the cultivation media. Furthermore, two weeks old seedlings were selected based on its uniformity and transferred to the polybag.

\section{Acetic acid pre-treatment and drought stress}

Four weeks old plants were pre-treated with $200 \mathrm{~mL}$ of acetic acid with different concentrations (15, 30, and 45 $\mathrm{mM}$ ) in the soil for 9 days. We used tap water to replace the acetic acid pre-treatment in the negative control plants. Meanwhile, positive control refers to Capsicum plants that was not subjected to acetic acid treatment but was subjected to drought stress. Subsequently, all treated plants were subjected to drought stress conditions by withholding the irrigation for 10 days.

\section{Morphological and physiological response assessments}

Morphological responses parameters included plant height, number of leaves, root length and dry weight of the panicles. All these morphological parameters were observed after 10 days of drought condition, at 54 days after planting (DAP). The plant height was measured from the soil surface to the tip of the longest leaf. The number of leaves and root length were counted and measured from the plant base to the tip of the longest root, respectively. The observation of panicle weight was carried out by harvesting the panicle parts. The dry weight of the samples were then measured.

Determination of Relative Water Content (RWC) was conducted according to Hapsoh et al. (2006) at 54 DAP. The RWC was evaluated before drought treatment (control; turgid plants) and after 10 days without watering (drought treatment). Nine uniform leaf disks $\left(1 \mathrm{~cm}^{2}\right)$ were selected and the RWC was calculated by the following equation :

$$
R W C=\frac{F W-D W}{T W-D W} X 100 \%
$$

Where: FW is the fresh weight, DW is dry weight that was calculated after drying in the oven at $70{ }^{\circ} \mathrm{C}$ for 24 hours, TW is the turgid weight that was calculated after the leaf disks were re-hydrated by soaking for $24 \mathrm{~h}$ in the dark.

Total chlorophyll and carotenoid content were observed after drought treatment at 54 DAP Total chlorophyll and carotenoid content were measured by preparing 1 gram of fresh leaf samples. The samples were then washed thoroughly with distilled water and extracted sing $80 \%$ acetone solvent. The homogeneous samples were the placed in a dark place for $12 \mathrm{~h}$. The supernatant was taken and then measured using spectrophotometer. For chlorophyll content, absorbance (O.D) was measured by at 645 and $663 \mathrm{~nm}$ wavelength (Rajput \& Patil 2017), while for carotenoids, the absorbance (O.D) was measured at 480 and $510 \mathrm{~nm}$ wavelength. the chlorophyll and carotenoid levels are calculated with the following formula :

$$
\begin{aligned}
& \text { Chlorophyll-a }(\mathrm{mg} / \mathrm{g} \text { fresh weight })=\frac{12.7(\mathrm{~A} 663)-2.69(\mathrm{~A} 645) \mathrm{x} \mathrm{V}}{1000} . \mathrm{W} \\
& \text { Chlorophyll-b }(\mathrm{mg} / \mathrm{g} \text { fresh weight })=\frac{22.9(\mathrm{~A} 645)-4.68(\mathrm{~A} 663) \mathrm{x} \mathrm{V}}{1000} . \mathrm{W} \\
& \text { Total Chlorophyll }(\mathrm{mg} / \mathrm{g} \text { fresh weight })=\frac{20.2(\mathrm{~A} 645)+8.02(\mathrm{~A} 663) \mathrm{x} \mathrm{V}}{1000} . \mathrm{W} \\
& \text { Carotenoid }(\mathrm{mg} / \mathrm{g} \text { fresh weight })=\frac{7.4(\mathrm{~A} 480)+1.49(\mathrm{~A} 510) \mathrm{x} \mathrm{V}}{1000} \mathrm{~W}
\end{aligned}
$$


Where: $\mathrm{A}$ is the absorbance at specific wavelength, $\mathrm{V}$ is the final volume of chlorophyll extract in acetone $80 \%$ and $\mathrm{W}$ is the fresh weight of extracted tissue (gr).

\section{The treatment design}

This study was designed and carried out using a factorial design method in a completely randomized design (CRD). The observed factors consisted of 2 factors. The first factor was accession consisting of 2 levels, namely Gambir Manis (GM) accession and Polman kuning (PK) accession. The second factor was acetic acid treatment consisting of 4 levels, namely concentrations of $0,15,30$, and $45 \mathrm{mM}$.

\section{Data analysis}

Data analysis was performed using SPSS series 25 to analyze the variance (ANOVA). The morpho-physiological data obtained were analyzed with two-way ANOVA at the 95\% confidence level and continued with the Tukey test.

\section{RESULTS AND DISCUSSION}

\section{Morphological parameters of the Setaria italica during drought stress}

Statistical analysis showed that interaction between acetic acid pre-treatment and foxtail millet accessions influenced the morphological parameters (plant height, number of leaves, and root length) of the plant under drought stress condition ( $\mathrm{p}$ value $<0.05$ ).

Our data showed that plant height of the two foxtail millet accessions was varied after being pre-treated with acetic acid. However, we noticed that the PK accession pre-treated with $15 \mathrm{mM}$ acetic acid possessed higher plant height than other pre-treated plants at different concentration of acetic acid (table 1). These results indicated that acetic acid pre-treatment might maintain the plant growth performance during drought stress. In addition, as with Utsumi et al. (2019), it depends on the plant genotype and the concentration of the acetic acid. Higher level of acetic acid concentrations might negatively affect plant height (Rahman et al. 2019).
Acetic acid has been reported to induce the biosynthesis of Abscisic Acid (ABA) and jasmonic acid (JA), plant hormones that function as an abiotic stress response. According to Kim et al. (2018), exogenous acetic acid was able to increase drought stress tolerance through the pathway of jasmonic acid and $\mathrm{H} 4$ histone acetylation. Furthermore, Histone acetylation can activate the downstream gene network which functions as an abiotic stress response and makes plants more tolerant to drought conditions. Numerous genes expression activation has been reported during drought stress conditions (Jadid et al. 2018). This adverse condition would generate perturbation in plant metabolisms. Decrease of turgor pressure which affects cell division and expansion has been reported to be responsible in declining plant growth compared to normal conditions (Sikuku and Onyango 2012). Cell expansion (cell enlargement) requires turgor pressure to extend the cell wall. In addition, osmotic stress might also inhibit the cytokinins which play a role in cell division and development (Karunadasa et al. 2020).

Significant reduction in the number of leaves have been observed in all GM treated plants compared to both negative and positive controls. Meanwhile, we observed that there were no significant difference in the number of leaves of PK plants compared to both negative and positive controls (Table 1). Our data also showed that PK accession have higher number of leaves in all acetic acid pretreatment compared to GM accession. Highest number of leaves were recorded in PK accession that pre-treated with $15 \mathrm{mM}$ of acetic acid (11.3 leaves). GM acetic acid-treated plants exhibited significant reduction of the number of leaves compared to the GM negative control plant. Meanwhile, we did not observe significant change in the number of leaves of the PK acetic acid-treated plants compared to the PK negative control plants (Table 1). Reduction of the number of leaves might be due to the plant response to reduce the transpiration rate during drought stress. Interestingly, treated PK plants exhibited good tolerance strategy to cope the drought stress, even though we also observed the presence of wilting leaves. These common features of wilting leaves after being stressed with drought might be back to normal after rewatering (Jadid et al. 2018). This suggest that PK accession is more adaptable to drought stress compared to the GM accession.

Table 1. The effect of acetic acid pre-treatment on the morphological parameters of two accession of foxtail millet under drought conditions

\begin{tabular}{lcccccc}
\hline \multirow{2}{*}{ Acetic acid treatments } & \multicolumn{2}{c}{ Means \pm SD } \\
\cline { 2 - 7 } & \multicolumn{2}{c}{ Plant height $(\mathbf{c m})$} & \multicolumn{2}{c}{ Number of leaves } & \multicolumn{2}{c}{ Root length (cm) } \\
\cline { 2 - 7 } & GM & PK & GM & PK & GM & PK \\
\hline Negative control & $131.6 \pm 2.89^{\mathrm{d}}$ & $168.3 \pm 2.89^{\mathrm{b}}$ & $17 \pm 1.0^{\mathrm{a}}$ & $11.3 \pm 1.2^{\mathrm{c}}$ & $36 \pm 1^{\mathrm{c}}$ & $30 \pm 0^{\mathrm{d}}$ \\
Positif control & $105.3 \pm 6.11^{\mathrm{e}}$ & $146.6 \pm 4.04^{\mathrm{c}}$ & $13.6 \pm 0.58^{\mathrm{b}}$ & $11 \pm 1.0^{\mathrm{c}}$ & $46.6 \pm 2.89^{\mathrm{a}}$ & $40 \pm 0^{\mathrm{b}}$ \\
$15 \mathrm{mM}$ & $98.3 \pm 0.58^{\mathrm{ef}}$ & $180,6 \pm 6,66^{\mathrm{a}}$ & $10.3 \pm 0.58^{\mathrm{c}}$ & $11.3 \pm 0.58^{\mathrm{c}}$ & $37 \pm 1.41^{\mathrm{bc}}$ & $39.3 \pm 1.2^{\mathrm{bc}}$ \\
$30 \mathrm{mM}$ & $98 \pm 2^{\mathrm{ef}}$ & $149 \pm 1.73^{\mathrm{c}}$ & $10.6 \pm 0.58^{\mathrm{c}}$ & $9.6 \pm 0.58^{\mathrm{c}}$ & $30.3 \pm 0.58^{\mathrm{d}}$ & $25.3 \pm 0.6^{\mathrm{e}}$ \\
$45 \mathrm{mM}$ & $93.6 \pm 2.89^{\mathrm{f}}$ & $122.3 \pm 4.04^{\mathrm{d}}$ & $10 \pm 0^{\mathrm{c}}$ & $10.6 \pm 0.58^{\mathrm{c}}$ & $25 \pm 0^{\mathrm{e}}$ & $24 \pm 0^{\mathrm{e}}$ \\
\hline
\end{tabular}

Note: the numbers with the same notation in the Tukey test are not significantly different $(\mathrm{P}<0.05)$. GM : Gambir Manis accession; PK: Polman Kuning accession 
Acetic acid pre-treatment induces ABA which plays a role in closing stomata on leaves. This might prevent loss of water during drought stress (Basu et al. 2016; Laxa et al. 2019). Another study has explained that acetic acid might induce antioxidant compounds that could protect photosynthetic apparatus from damages due to the increase of reactive oxygen species (ROS) (Rahman et al. 2019). in addition, that acetic acid pre-treatment has been reported to increase various ABA responsive genes (Utsumi et al. 2019). Some previous research has shown that ABA plays important role in plant defence mechanisms against abiotic stress (Jadid et al. 2017).

Root length was also slightly affected in acetic acid pretreated accessions. The root length of the two accessions at the age of 54 DAS varied, ranging from $24-46.6 \mathrm{~cm}$. PK pre-treated accessions performed good root growth performance compared to the GM treated plants. Highest root length was obtained in the PK pre-treated with $15 \mathrm{mM}$ of acetic acid $(39.3 \mathrm{~cm})$ compared to other PK and GM pretreated plants (Table 1). In addition, we observed that there was no significant difference between PK pre-treated with $15 \mathrm{mM}$ acetic acid and negative control (Figure 1). It might suggest that $15 \mathrm{mM}$ acetic acid might be efficient concentration to enhance the tolerance of PK plants to drought stress. It is assumed that acetic acid pretreatment can minimize the inhibitory effect on root length through the jasmonic acid signaling. Jasmonic acid is a phytohormone that plays an important role during the abiotic stress (Liu et al. 2012). The results of this study are consistent with Beyene et al. (2015) who reported that root length of sorghum and millet increased under drought conditions. However, higher concentration of acetic acid resulted in a decrease of root length in both accession plants. This indicated that high concentration of acetic acid inhibits root growth of $S$. italica. Root growth inhibition due to drought stress has been also reported in maize (Allen and Allen, 2020), wheat (Nio et al. 2011), and rice (Seo et al. 2011). In addition, we also observed that there was an increase of lateral root formation after drought conditions (Figure 1). The development of lateral root in response to drought stress is considered as common plant adaptation (Miftahudin et al. 2020). The root architecture of the GM and PK accessions was different, presumably influenced by the genotype of the plants and acetic acid pre-treatment. Sharp et al. (2004) also demonstrated that difference of plant root architecture under drought stress is also genetically controlled. Furthermore, acetic acid pretreatment has been reported to enhance the ability of plant root to efficiently absorbs water and soil nutrients through root architecture modification (Rahman et al. 2019).

\section{Effect of acetic acid pre-treatment on the physiology of Setaria italica in drought conditions \\ Relative water content (RWC)}

In order to determine the physiological effect of acetic acid pre-treatment to enhance drought avoidance of the two foxtail millet accessions, we measured the chlorophyll, total carotenoid and the relative water content (RWC) of the plants aged 54 days after planting (DAP). Phenotypically, the leaves of the foxtail millet accessions showed to be yellowish (starting from the basal of the plants) following the drought conditions periods drought stress (Figure 2).

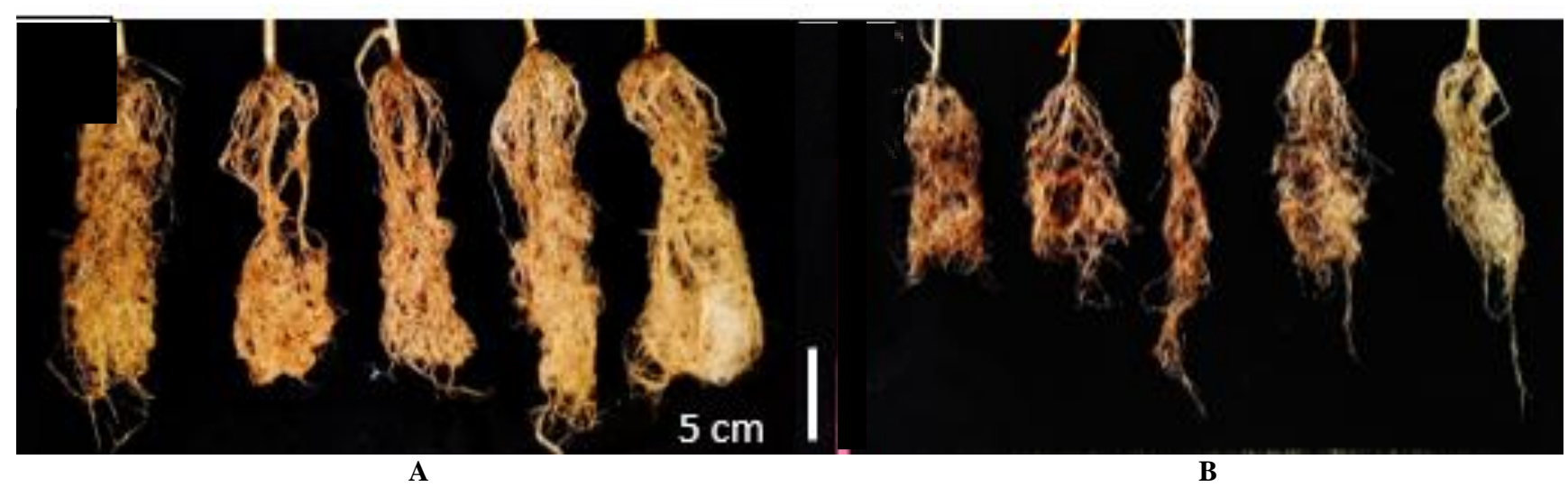

Figure 1. Root architecture of Setaria italica after being treated with acetic acid and drought stress. A. GM accession, B. PK accession with acetic acid pre-treatment with concentrations of $45 \mathrm{mM}, 30 \mathrm{mM}, 15 \mathrm{mM}$, positive control, and negative control (left to right) after drought stress conditions. 


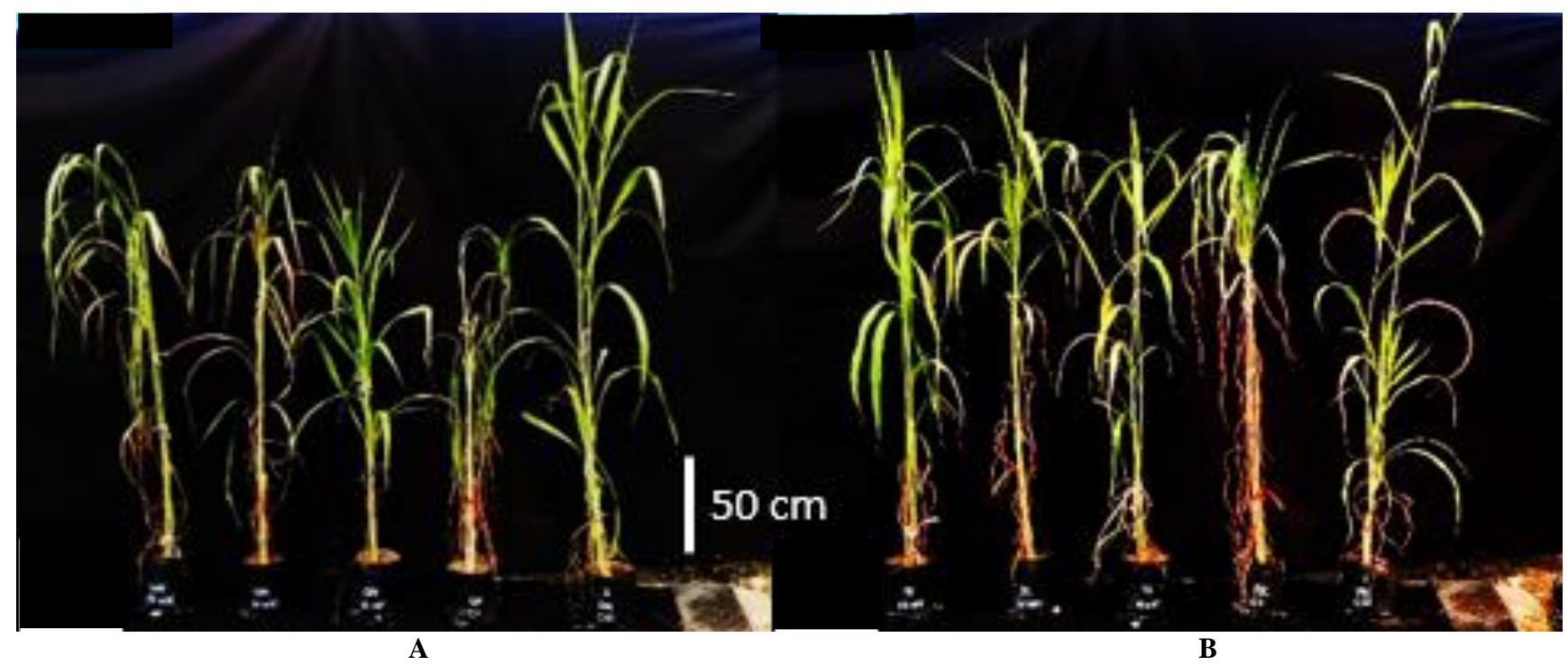

Figure 2. Morphological effects of acetic acid pre-treatment on foxtail millet (A) GM accession (B) PK accession with acetic acid concentrations of $45 \mathrm{mM}, 30 \mathrm{mM}, 15 \mathrm{mM}$, positif control, and negative control (left to right) under drought conditions

RWC is a measure of water status in plants as a physiological consequence of groundwater content (Ying et al. 2015). RWC is related to the ability to absorb water from the soil and the ability of plants to control water loss through stomata (Parkash and Singh 2020). In addition, the presence of RWC reduction illustrates changes in osmotic potential, transpiration rate and water absorption from the soil in drought conditions (Utsumi et al. 2019). Our statistical analysis showed that the interaction between acetic acid concentration and accession treatment did not significantly influence the RWC ( $\mathrm{p}$ value > 0.05). However, the percentage of RWC of GM plants pre-treated by $30 \mathrm{mM}(72.36 \%)$ were just slightly below the RWC of GM negative control plants $(81.14 \%)$ after drought stress condition. Meanwhile, PK pre-treated with 30 and $45 \mathrm{mM}$ possess more water content after drought stress condition compared to PK pre-treated with $15 \mathrm{mM}$ (Figure 3). Even though the interaction between acetic acid concentration and accession treatment did not significantly influence the RWC, GM accessions were thought to be more able to maintain the water content during drought stress than the PK accession plants (Figure 3). Slight difference between both GM/PK pre-treated accessions and their negative controls indicates that acetic acid is able to maintain the water status of the treated plants during drought stress (Utsumi et al. 2019)

\section{Total chlorophyll and carotenoid content}

Total chlorophyll was shown to be not significantly different between pre-treated plants and control groups. Even though, we observed slight decrease of the total chlorophyll of the pre-treated plants compared to nontreated plants (Figure 4). These results suggest that acetic acid pre-treatment was able to minimize the negative effect of drought stress in perturbing the photosynthetic apparatus of the cells. Our results are also supported by the results from previous study demonstrating that total chlorophyll did not change when cassava was previously treated with acetic acid until 4 days of stressed with drought conditions. However, the chlorophyll content might decrease following the degree of drought conditions (Rasheed et al. 2018; Ajithkumar and Panneerselvam 2013). However, we observed different chlorophyll content between the two foxtail millet accessions. Chlorophyll content of the GM accessions were higher than those observed in the PK accession plants (Figure 4). This result suggests that genetic of the plants influence their responses against drought stress (Sharp et al. 2004). Highest chlorophyll content in the drought-treated plants were demonstrated in the GM accessions that were pre-treated by $45 \mathrm{mM}$ of acetic acid $(0.23 \mathrm{mg} / \mathrm{g} \mathrm{FW})$. Similar results were also obtained for the total carotenoid content. Our data showed that there was no significant difference of the carotenoid content observed in treated plants compared with controls. Interestingly, the carotenoid content between negative control plants $(0 \mathrm{mM}$ of acetic acid) and $45 \mathrm{mM}$ PK pretreated plants were similar (Figure 5). It suggests that the acetic acid might prevent the cellular perturbation in both photosynthetic apparatus and prevent the enzymatic damage of many enzymatic antioxidants within the cytoplasm. Different profile of carotenoid content was observed between the two acetic acid-pretreated accessions of foxtail millet in response to drought stress. GM accessions possessed higher carotenoid content than PK accessions.

Acetic acid treatment is also reported to increase catalase activity, an enzyme that plays a role in accelerating the breakdown of $\mathrm{H}_{2} \mathrm{O}_{2}$ into water and oxygen (Rahman et al. 2019). Other study has also demonstrated that there is an increase of CAT accumulation after being pre-treated with acetic acid to scavange the excessive hydrogen peroxide produced during drought stress condition (Utsumi et al. 2019). Stable carotenoid content in plants is necessary since it acts as an antioxidant, capturing $1 \mathrm{O}_{2}$ to inhibit oxidative damage of the photosynthetic apparatus. 
Moreover, carotenoids act as precursors for signaling molecules that influence plant development and the biotic /

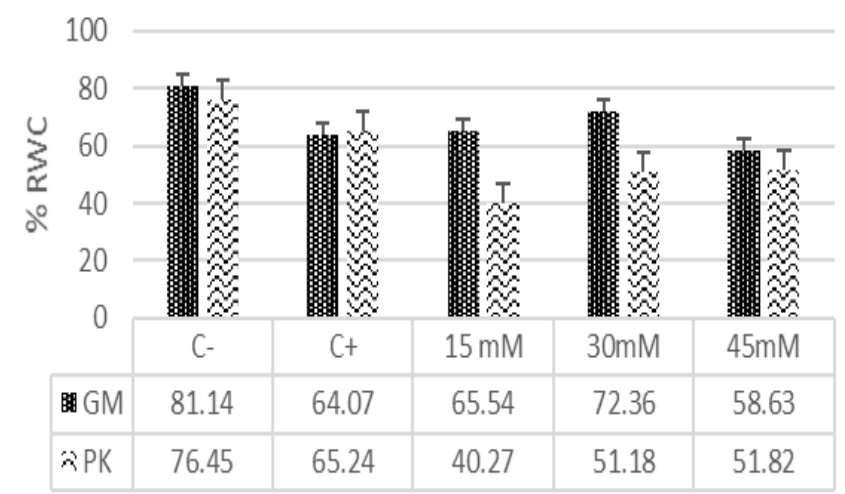

Figure 3. The relative water content (RWC) of Gambir Manis and Polman Kuning accessions after being pre-treated with acetic acids and subjected to drought stress conditions. $\mathrm{C}$ - and $\mathrm{C}+$ refer to negative control and positive control, respectively

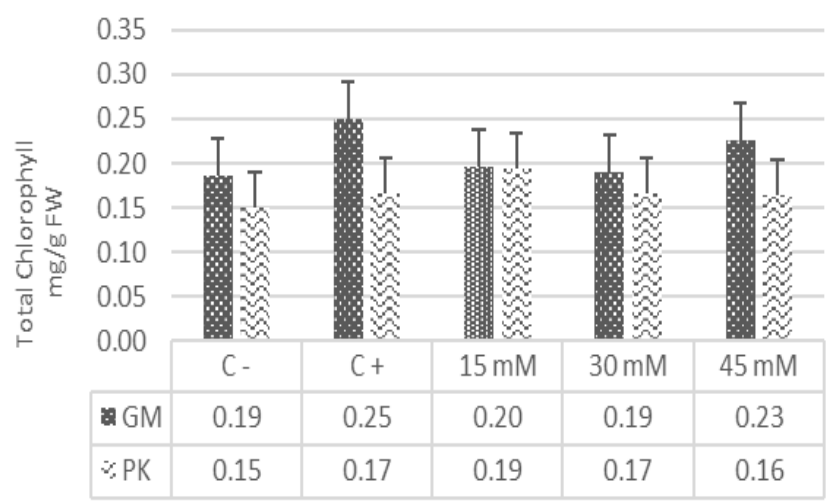

Figure 4. Total chlorophyll content of Setaria italica pre-treated with acetic acid under drought conditions. $\mathrm{C}$ - and $\mathrm{C}+$ refer to negative control and positive control, respectively abiotic stress response, including the biosynthesis of ABA, GA, and strigolactones (Jadid et al. 2011).

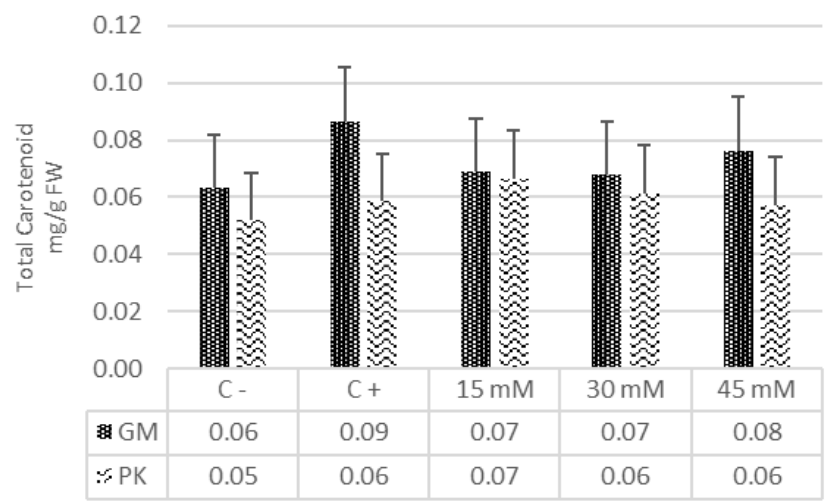

Figure 5. Total carotenoid content of Setaria italica pre-treated with acetic acid under drought conditions. $\mathrm{C}$ - and $\mathrm{C}+$ refer to negative control and positive control, respectively

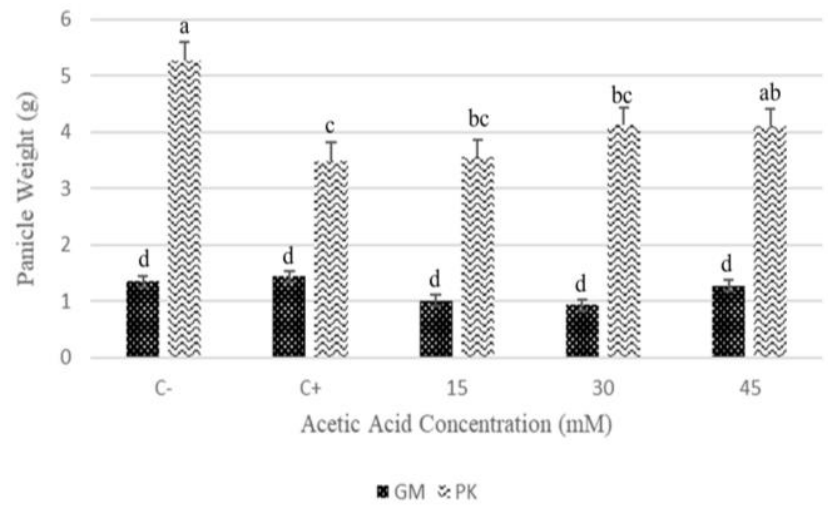

Figure 7. Panicle dry weight of foxtail millet with acetic acid pretreatment under drought conditions. $\mathrm{C}$ - and $\mathrm{C}+$ refer to negative control and positive control, respectively

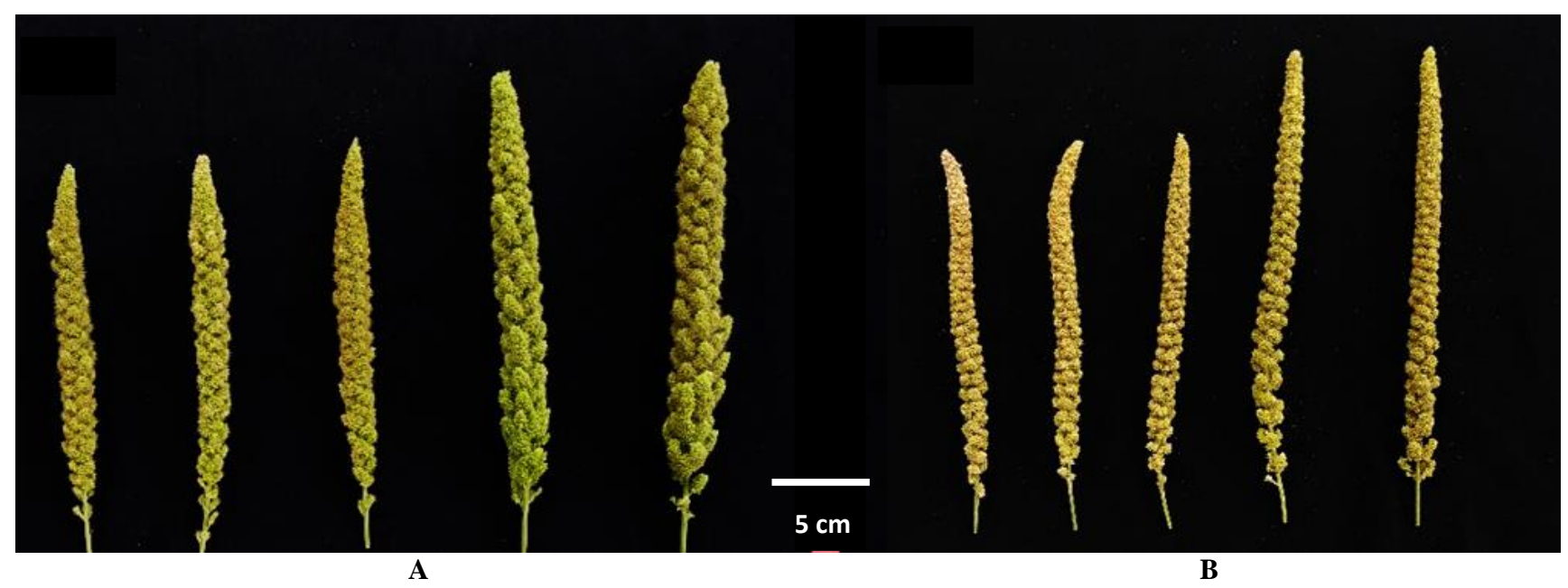

Figure 6. The panicles of two accessions of Setaria italica after being stressed in drought conditions. A: Gambir Manis accessions, B: Polman Kuning accessions. All the plants were previously subjected to acetic acid pre-treatments (negative control, positive control, 15, $30,45 \mathrm{mM}$; left to right). 


\section{Panicle weight}

We also measured the effect of acetic acid pretreatments to the productivity of the foxtail millet during drought stress conditions by evaluating the dry weight (DW) of the panicles. The panicles were harvested at the age of 54 DAP. All the panicles were normal after being stressed with drought (Figure 6). Our statistical analysis showed that the interaction between acetic acid concentration and accession significantly influence the panicle weight (Figure 7). We observed that PK accession treated with $45 \mathrm{mM}$ possessed heavier panicle weight (4.1 g) compared to others. This is slightly below the PK negative control plant. This indicated that acetic acid pretreatment might help PK plants cope the adverse environment generated by drought stress. Meanwhile, the panicles DW of the GM accession plants were relatively similar in all GM acetic acid treated plants and both GM negative and positive control plants. Even though, we observed that GM accession plants are more susceptible to water deficit stress than PK accession plants. In addition, dry weight of the PK plants is genetically heavier panicle than the GM plants. However, acetic acid pre-treatment was able to stably maintain the dry weight of the GM panicle after drought condition compared to those observed in the PK plants. Panicle dry weight reduction is generally observed when foxtail millet facing drought stress condition (Matsuura and An, 2020). Grain yield under drought condition might be influenced by grain yield potential and genotype susceptibility to water stress (Fisher and Maurer, 1978). Tang et al. 2017 also demonstrated some $S$. italica cultivars demonstrated different panicle weight response under water stress. It has been evaluated that the brassinosteroid (BR) biosynthesis genes were up regulated in the resistant cultivar. In addition, overexpression of the gene involved in the regulation of BR was reported to be responsible to wider leaves and better grain yield of Brassica napus (Sahni et al. 2016). This demonstrates that BR is important for plant response against drought stress (Planas-Riverola et al. 2019) and might be correlated with abscisic acid (ABA). The later is well-known phytohormone which plays an important role in regulating stress signals and is critical for plant growth and development under both biotic and abiotic stress (Tuteja et al. 2007). Interestingly, acetic acid pre-treatment has been reported to activate the ABA biosynthesis. Moreover, acetic acid also upregulates the expression of ABA signaling-related genes including ABI2, OST1, AHG1 and AFP2 (Nishimura et al. 2007; Lynch et al. 2017). However, further investigation is needed in order to explore ABA and BR crosstalk of acetic acid-treated plants under water deficit condition.

\section{ACKNOWLEDGEMENTS}

The authors greatly acknowledge the Ministry of Research and Technology of the Republic of Indonesia who finance this study through Master Research (Contract No. 1411/PKS/ITS/2020). We also thank to the Research
Center for Agri-food and Biotechnology, Institut Teknologi Sepuluh Nopember, Surabaya, Indonesia who has supported this study.

\section{REFERENCES}

Ahanger MA, Akram NA, Ashraf M, Alyemeni MN, Wijaya L, Ahmad P. 2017. Plant responses to environmental stresses-From gene to biotechnology. AoB Plants 9: 4. DOI: 10.1093/aobpla/plx025.

Ajithkumar IP, Panneerselvam R. 2013. Osmolyte accumulation, photosynthetic pigment and growth of Setaria italica (L.) P. Beauv. under drought stress. Asian Pac J Reprod 2 (3): 220-224. DOI: 10.1016/S2305-0500 (13)60151-7.

Allen MM, Allen DJ. 2020. Biostimulant potential of acetic acid under drought stress is confounded by ph-dependent root growth inhibition. Front Plant Sci. 11: 647. DOI: 10.3389/fpls.2020.00647.

Almaski A, Thondre S, Lightowler H, Coe S. 2017. Determination of the polyphenol and antioxidant activity of different types and forms of millet. Proc Nutr Soc 76 (OCE1): E5. DOI: $10.1017 /$ S0029665117000052.

Amadou I, Gounga ME, Le G. 2013. Millets : Nutritional composition, some health benefits and processing - A Review. Emirates J Food Agric 25 (7): 501-508. DOI: 10.9755/ejfa.v25i7.12045.

Amadou I, Moussa SMA. 2018. Processing and sensory evaluation of germinated millets varieties grains flours. MOJ Food Process Technol 6 (1): 151-153. DOI: 10.15406/mojfpt.2018.06.00158.

Asada K. 2006. Production and scavenging of reactive oxygen species in chloroplasts and their functions. Plant Physiol 141 (2): 391-396. DOI: 10.1104/pp.106.082040.

Basu S, Ramegowda V, Kumar A, Pereira A. 2016. Plant adaptation to drought stress. F1000 Research 5: 1554. DOI: 10.12688/f1000research.7678.1.

Begum F, Sultana R, Nessa A. 2013. Screening of drought tolerant foxtail millet (Setaria italica Beauv.) germplasm. Bangladesh J Sci Industr Res 48 (4): 265-270.

Beyene A, Hussien S, Pangirayi T, Mark L. 2015. Physiological mechanisms of drought tolerance in sorghum, genetic basis and breeding methods: A review. Afr J Agric Res 10 (31): 3029-3040. DOI: 10.5897/ajar2015.9595.

Fisher RA, Maurer R. 1978. Drought resistance in spring wheat cultivars. C. Grain yield responses. Austr J Agric Res 29: 897-912. DOI: 10.1071/AR9780897.

Hapsoh, Yahya S, Oelim TMH, Purwoko BS. 2006. Respons fisiologi beberapa genotipe kedelai yang bersimbiosis dengan MVA terhadap berbagai tingkat cekaman kekeringan. Hayati J Biosci 13 (2): 43-48. DOI: 10.1016/S1978-3019 (16)30379-5. [Indonesian]

Jadid N, Estiasih E, Saputro TB, Purwani KI, Hidayati D, Permatasari EV, Kurniawan WD. 2018. Expression pattern of drought-responsive genes in burley tobacco under in vitro water deficit. J Physics 1040: 012004. DOI: 10.1088/1742-6596/1040/1/012004.

Jadid N, Maziyah R, Nurcahyani DW, Mubarokah NR. 2017. Growth and physiological responses of some Capsicum frutescens varieties to copper stress. AIP Conf Proc 1854: 020018. DOI: 10.1063/1.4985409.

Jadid N, Mialoundama AS, Heintz D, Ayoub D, Erhardt M, Mutterer J, Meyer D, Alioua A, Van Dorsselaer A, Rahier A, Camara B, Bouvier F. 2011. DOLICHOL PHOSPHATE MANNOSE SYNTHASE1 mediates the biogenesis of isoprenyl-linked glycans and influences development, stress response, and ammonium hypersensitivity in Arabidopsis. Plant Cell 23 (5): 1985-2005. DOI: 10.1105/tpc.111.083634.

Jali MV, Kamatar MY, Jali SM, Hiremath MB, Naik RK. 2012. Efficacy of value added foxtail millet therapeutic food in the management of diabetes and dyslipidamea in type 2 diabetic patients. Recent Res Sci Technol 4 (7): 3-4.

Karunadasa SS, Kurepa J, Shull TE, Smalle JA. 2020. Cytokinin-induced protein synthesis suppresses growth and osmotic stress tolerance. New Phytol 227 (1): 50-64. DOI: 10.1111/nph.16519.

Kim, J.-M, To TK, Matsui A, Tanoi K, Natsuko IK. 2018. Acetatemediated novel survival strategy against drought in plants. Nature Plants 17097: 3-5. DOI: 10.1038/nplants.2017.97. 
Kotchoni SO, Kuhns C, Ditzer A, Kirch HH, Bartels D. 2006. Overexpression of different aldehyde dehydrogenase genes in Arabidopsis thaliana confers tolerance to abiotic stress and protects plants against lipid peroxidation and oxidative stress. Plant Cell Environ 29 (6): 1033-1048. DOI: 10.1111/j.1365-3040.2005.01458.x.

Kumari R, Dikshit N, Sharma D. 2011. Analysis of molecular genetic diversity in a representative collection of foxtail millet (Setaria italica (L .) $\mathrm{P}$. Beauv) from different agro-ecological regions of India. Physiol Mol Biol Plants 17: 363-374. DOI: 10.1007/s12298-0110085-3.

Lata C, Sahu PP, Prasad M. 2010. Biochemical and Biophysical Research Communications Comparative transcriptome analysis of differentially expressed genes in foxtail millet (Setaria italica L.) during dehydration stress. Biochem Biophys Res Commun 393 (4): 720-727. DOI: 10.1016/j.bbrc.2010.02.068.

Laxa M, Liebthal M, Telman W, Chibani K, Dietz KJ. 2019. The role of the plant antioxidant system in drought tolerance. Antioxidants 8 (4). DOI: $10.3390 /$ antiox 8040094 .

Lapuimakuni S, Khumaida N, Ardie SW. 2018. Short Communication: Evaluation of drought tolerance indices for genotype selection of foxtail millet (Setaria italica). Trop Drylands 2 (2): 37-40. 10.13057/tropdrylands/t020201.

Liu X, Li F, Tang J, Wang W, Zhang F, Wang G, et al. 2012. Activation of the jasmonic acid pathway by depletion of the hydroperoxide lyase OsHPL3 reveals crosstalk between the HPL and AOS branches of the Oxylipin pathway in rice. PLoS ONE 7 (11): e50089. DOI: 10.1371/journal.pone.0050089.

Liu Z, Bai G, Zhang D, Zhu C, Xia X, Cheng R, Shi Z. 2011. Genetic diversity and population structure of elite foxtail millet [Setaria itálica (L.) P.Beauv.] germplasm in China. Crop Sci 51 (4): $1655-$ 1664. DOI: 10.2135/cropsci2010.11.0643.

Lynch TJ, Erickson BJ, Miller DR, Finkelstein RR. 2017. ABI5-binding proteins (AFPs) alter transcription of ABA-induced genes via a variety of interactions with chromatin modifiers. Plant Mol Biol 93: 403-418. DOI: 10.1007/s11103-016-0569-1.

Matsuura A, An P. 2020. Factors related water and dry matter during preand post-heading in four millet species under severe water deficit Plant Prod Sci 23 (1): 28-38. DOI: 10.1080/1343943X.2019.1698969.

Miftahudin, Putri RE, Chikmawati. 2020. Vegetative morphophysiological responses of four rice cultivars to drought stress. Biodiversitas 21: 3727-3734. 10.13057/biodiv/d210840.

Nio SA, Cawthray GR, Wade LJ, Colmer TD. 2011. Pattern of solutes accumulated during leaf osmotic adjustment as related to duration of water deficit for wheat at the reproductive stage. Plant Physiol Biochem 49: 1126-1137. DOI: 10.1016/j.plaphy.2011.05.011.

Nishimura N, Yoshida T, Kitahata N, Asami T, Shinozaki K, Hirayama T 2007. ABA-hypersensitive germination1 encodes a protein phosphatase $2 \mathrm{C}$, an essential component of abscisic acid signaling in Arabidopsis seed. Plant J 50: 935-949.

Pan J, Li Z, Wang Q, Garrell AK, Liu M, Guan Y, Zhou W. 2018. Comparative proteomic investigation of drought responses in foxtail millet. BMC Plant Biol 18: 315. DOI: 10.1186/s12870-018-1533-9.

Parkash V, Singh S. 2020. A review on potential plant-based water stress indicators for vegetable crops. Sustainability 12 (10): 3945. DOI: $10.3390 /$ su 12103945 .

Rahman M, Mostofa MG, Rahman A. 2019. Acetic acid : a cost-effective agent for mitigation of seawater-induced salt toxicity in mung bean. Sci Rep 9: 15186. DOI: 10.1038/s41598-019-51178-w.
Rajput RD, Patil RP. 2017. The comparative study on spectrophotometric analysis of chlorophyll and carotenoids pigments from nonleguminous fodder crops. Intl J Innov Sci Eng Technol 4 (7): 140148.

Rasheed S, Bashir K, Kim JM, Ando M, Tanaka M, Seki M. 2018. The modulation of acetic acid pathway genes in Arabidopsis improves survival under drought stress. Sci Rep 8 (1): 7831. DOI: 10.1038/s41598-018-26103-2.

Sahni S, Prasad BD, Liu Q, Grbic V, Sharpe A, Singh SP, Krishna P. 2016. Overexpression of the brassinosteroid biosynthetic gene DWF4 in Brassica napus simultaneously increases seed yield and stress tolerance. Sci Rep 6: 28298. DOI: 10.1038/srep28298.

Seo JS, Joo J, Kim MJ, Kim YK, Nahm BH, Song SI, Cheong JJ, Lee JS, Kim JK, Choi YD. 2011. OsbHLH148, a basic helix-loop-helix protein, interacts with OsJAZ proteins in a jasmonate signaling pathway leading to drought tolerance in rice. Plant J 65 (6):907-921. DOI: $10.1111 /$ j.1365-313X.2010.04477.x.

Sikuku P, Onyango J. 2012. Physiological and biochemical responses of five nerica rice varieties (Oryza sativa L.) to water deficit at vegetative and reproductive stage. Agric Biol J North Amer 3 (3): 93 104. DOI: 10.5251/abjna.2012.3.3.93.104.

Sulistiyowati, E. 2015. Karakterisasi sepuluh aksesi hotong (Setaria italica (L.) Beauv.) di rumah kaca. [Hon. Thesis]. Institut Pertanian Bogor, Bogor. [Indonesian]

Tang S, Li L, Wang,Y, Chen Q, Zhang W, Jia G. 2017. Genotype-specific physiological and transcriptomic responses to drought stress in Setaria italica (an emerging model for Panicoideae grasses). Sci Rep 7: 10009. DOI: 10.1038/s41598-017-08854-6.

Tuteja N. 2007. Abscisic acid and abiotic stress signaling. Plant Sign Behav 2 (3): 135-138. DOI: 10.4161/psb.2.3.4156

Utsumi Y, Utsumi C, Tanaka M, Ha CV, Takahashi S, Matsui A et al. 2019. Acetic acid treatment enhances drought avoidance in cassava (Manihot esculenta crantz). Front Plant Sci 10: 521. DOI: 10.3389/fpls.2019.00521.

Veeranagamallaiah G, Chandraobulreddy P, Jyothsnakumari G, Sudhakar C. 2007. Glutamine synthetase expression and pyrroline-5carboxylate reductase activity influence proline accumulation in two cultivars of foxtail millet (Setaria italica L.) with differential salt sensitivity. Environ Exp Bot 60 (2): 239-244. DOI: 10.1016/j.envexpbot.2006.10.012.

Wise R, Naylor A. 1987. Chilling-enhanced photooxidation: evidence for the role of singlet oxygen and superoxide in the breakdown of pigments and endogenous antioxidants. Plant Physiol 83 (2): 278-282. DOI: $10.1104 / \mathrm{pp} .83 .2 .278$.

Xu B-Q, Gao X-Li, Gao J-F, Li J, Yang P, Feng B-Li. 2019. Transcriptome profiling using RNA-seq to provide insights into foxtail millet seedling tolerance to short-term water deficit stress induced by PEG-6000. J Integr Agric 18 (11): 2457-2471. DOI: 10.1016/S2095-3119 (19)62576-1.

Ying YQ, Song LL, Jacobs DF, Mei L, Liu P, Jin SH, Wu JS. 2015. Physiological response to drought stress in Camptotheca acuminata seedlings from two provenances. Front Plant Sci 6: 361. DOI: 10.3389/fpls.2015.00361.

Zhu C, Ming C, Zhao-Shi X, Lian-Cheng L, Xue-Ping C, You-Zhi M. 2014. Characteristics and expression patterns of the Aldehyde Dehydrogenase (ALDH) gene superfamily of foxtail millet (Setaria italica L.). PLoS ONE 9 (7). DOI: 10.1371/journal.pone.0101136.

Zlatev ZS, Yordanov IT. 2005. Effects of soil drought on photosynthesis and chlorophyll fluorescence in bean plants. Bulgarian J Plant Physiol Physiol 30 (3-4): 3-18. 